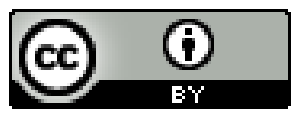

\title{
O PERFIL RACIAL DA REGIÃO NORTE E O NEGRO GUAPOREANO NOS DOCUMENTOS DO ARQUIVO PÚBLICO DE
}

\author{
MATO GROSSO: 1901-1943
}

\begin{abstract}
Paulo Sérgio Dutra ${ }^{1}$
Resumo: O texto apresenta dados censitários sobre o perfil racial da população da Região Norte, do Território Federal do Guaporé, dos municípios deste e ainda centra suas atenções em registros históricos sobre o negro guaporeano em documentos presentes no Arquivo Público do Estado de Mato Grosso, (1901/1943). O objetivo é contribuir com pesquisas que trazem como tema "as populações negras". Nesse sentido, ao construí-lo, utilizou-se a pesquisa bibliográfica, a análise de documentos e a História Oral. Considerando, os dados levantados, constatou-se uma superioridade demográfica negra nos espaços geográficos que compunham a Região Norte, no Território Federal do Guaporé, bem como em seus municípios. Considerando a documentação, ressalta-se que as mulheres negras protagonizam os conteúdos registrados nestes, principalmente os endereçados à instrução pública.
\end{abstract}

Palavras-Chave: Educação; Documentos; Perfil Racial; Guaporé; Assinaturas.

\section{THE RACIAL PROFILE OF THE NORTHERN REGION AND THE GUAPOREAN NEGRO IN THE DOCUMENTS OF THE ARCHIVE OF MATO GROSSO: 1901-1943}

\begin{abstract}
Abstratc: The text presents census data on the racial profile of the population of the Northern Region, the Federal Territory of Guaporé, and its municipalities and still focuses its attention on historical records on the Guaporean Negro in documents present in the Public Archive of the State of Mato Grosso, (1901/1943). The objective is to contribute to research that has as its theme "black populations". In this sense, when building it, bibliographic research, document analysis and Oral History were used.

\footnotetext{
${ }^{1}$ Doutor em Educação pela Universidade Federal Fluminense, Mestre em Educação pela Universidade Federal de Mato grosso, graduado em Licenciatura em Pedagogia pela Universidade Federal de Rondônia. Professor Adjunto da Universidade Federal de Rondônia, leciona no Curso de Graduação em Pedagogia Licenciatura. É líder do Grupo de Estudos e Pesquisa em Relações Raciais e Migração e integra da Rede de Pesquisa, Ensino e Extensão da Educação nas Regiões Centro-Oeste e Norte do Brasil e na América Latina - RECONAL-Edu. E-mail: paulodutra@unir.br
}

Revista da ABPN • v. 12, n. Ed. Especial - Caderno Temático: "Africanos, escravizados, libertos biografias, imagens e experiências atlânticas” • agosto de 2020, p. 613-636 
Considering the data collected, a black demographic superiority was found in the geographic spaces that made up the North Region, in the Federal Territory of Guaporé, as well as in its municipalities. Considering the documentation, it is emphasized that black women are the protagonists of the contents registered in these, mainly those addressed to public instruction.

Keywords: Education; Documents; Racial Profile; Guaporé; Subscriptions

\section{EL PERFIL RACIAL DE LA REGIÓN NORTE Y EL NEGRO GUAPOREAN EN LOS DOCUMENTOS DEL ARCHIVO DE MATO GROSSO: 1901-1943}

Resumen: El texto presenta datos del censo sobre el perfil racial de la población de la Región Norte, el Territorio Federal de Guaporé, sus municipios y aún enfoca su atención en los registros históricos sobre el Negro Guaporean en documentos presentes en el Archivo Público del Estado de Mato Grosso, (1901/1943). El objetivo es contribuir a la investigación que tiene como tema "poblaciones negras". En este sentido, al construirlo, se utilizó la investigación bibliográfica, el análisis de documentos y la historia oral. Teniendo en cuenta los datos recopilados, se encontró una superioridad demográfica negra en los espacios geográficos que componían la Región Norte, en el Territorio Federal de Guaporé, así como en sus municipios. Considerando la documentación, se enfatiza que las mujeres negras son las protagonistas de los contenidos registrados en estos, principalmente aquellos dirigidos a la instrucción pública.

Palavras-clave: Educación; Documentos; Perfil racial; Guaporé; Suscripciones

\section{LE PROFIL RACIAL DE LA REGION DU NORD ET DU NEGRE GUAPOREEN DANS LES DOCUMENTS DES ARCHIVES DU MATO GROSSO: 1901-1943}

Résumé: Le texte présente des données de recensement sur le profil racial de la population de la région du Nord, du Territoire fédéral de Guaporé, de ses municipalités et concentre toujours son attention sur les documents historiques sur le nègre de Guaporean dans des documents présents dans les archives publiques de l'État du Mato Grosso, (1901/1943). L'objectif est de contribuer à une recherche qui a pour thème «les populations noires». En ce sens, lors de sa construction, la recherche bibliographique, l'analyse de documents et l'histoire orale ont été utilisées. Compte tenu des données recueillies, une supériorité démographique noire a été constatée dans les espaces géographiques qui composent la Région Nord, dans le Territoire fédéral de Guaporé, ainsi que dans ses communes. Compte tenu de la documentation, il est souligné que les femmes noires sont les protagonistes des contenus enregistrés dans ces derniers, principalement ceux destinés à l'instruction publique.

Mots-clés: L'éducation; Documents; Profil racial; Guaporé; Abonnements.

Revista da ABPN • v. 12, n. Ed. Especial - Caderno Temático: "Africanos, escravizados, libertos biografias, imagens e experiências atlânticas" • agosto de 2020 , p. 613-636 


\section{INTRODUÇÃO}

O presente texto traz contribuições sobre o perfil racial da população na Região Norte por meio do Censo de 1950, e trata ainda das experiências vivenciadas por homens negros e mulheres negras na região do Vale do Guaporé e que estão registradas em diversos tipos de documentos guardados no Arquivo Publico do Estado de Mato Grosso - APMT, localizado na cidade de Cuiabá/MT. O texto em tela possibilita, a construção de olhares sobre as pesquisas que trazem como tema "as populações negras e afrodescendentes na Amazônia”. De outro modo, o texto também assume uma contrariedade àquilo que Aquino, Santana, Santana e Junior (2013) chamaram de "invisibilidade do negro" na produção do conhecimento, ao trazer para o centro do debate dados recenseados sobre a população negra na região Norte, em um território e seus municípios constitutivos.

A este respeito, assinala-se que o estudo está estruturado da seguinte forma: na primeira parte apresenta-se um panorama sobre a composição do perfil racial da população presente na Região Norte, no Território Federal do Guaporé e nos municípios que o compunham em conformidade com o Censo de 1950 publicado em 1957. Na segunda parte o/a leitor/leitora irá percorrer o caminho que ilustra passagens sobre o negro guaproreano nos registros dos documentos que estão guardados no Arquivo Público de Mato Grosso e em alguns acervos particulares. Na terceira e última parte, traz-se a luz um cenário contendo informações sobre mulheres negras guaporeanas, onde apresenta-se uma breve trajetória de duas professoras negras: Emília Bringel Guerra e Paula Gomes de Oliveira. Finaliza-se o escrito com as considerações finais.

\section{POPULAÇÃO DOS ESTADOS E TERRITÓRIOS QUE COMPUNHAM A REGIÃO NORTE CONFORME DADOS NA OCASIÃO DO IBGE NO CENSO DE 1950.}

O Recenseamento de 1950 foi a sexta edição de contagem da população brasileira realizada no país (IBGE, 1957, p. VII), desse modo, o Censo Demográfico foi dividido em três partes, a saber: demografia constando de quarenta e seis tabelas,

Revista da ABPN • v. 12, n. Ed. Especial - Caderno Temático: "Africanos, escravizados, libertos biografias, imagens e experiências atlânticas" • agosto de 2020, 
famílias constando de quatro tabelas e domicílios constando de seis tabelas. ${ }^{2}$ Nesse sentido, a tabela de número um intitulada "população presente, na data dos recenseamentos gerais, segundo alguns dos caracteres individuais", apresentou informações sobre oito quesitos, sendo: sexo, idade, cor, estado conjugal, religião, nacionalidade e instrução. Assim, ressalta-se que destes oito quesitos apresentados nesta tabela do referido senso, neste estudo centrou-se atenção apenas no quesito "cor".

A este respeito, a partir deste quesito, apresentou-se no presente texto um demonstrativo de sete (7) quadros, que informam ao leitor e/ou leitora em dados percentuais, a presença dentro das categorias raciais utilizadas pelo Instituto Brasileiro de Geografia e Estatística - IBGE, tais como: branco, preto, pardo e amarelo para contagem da população brasileira no Censo de 1950. Nesse sentido, para um entendimento sobre a contagem populacional do Brasil naquele momento a respeito do quesito cor, o IBGE (1957, v. 1, p. xvii-xviii) apresentou um esclarecimento sobre o ajuntamento das pessoas nas categorias utilizadas por este, da seguinte forma: [...] Côr [sic]: Distribui-se a população, segundo a côr, em quatro grupos - brancos, pretos, amarelos e pardos -, incluindo neste último os índios e os que se declararam mulatos, caboclos, cafuzos etc. ${ }^{3}$

Desse modo, o documento em questão destacou ainda, que a experiência censitária brasileira demonstrava as dificuldades que se opunham à coleta de informações relativas a cor (IDEM, IBIDEM). Assinalou reconhecer tal circunstância, julgando-se oportuno proceder a pesquisa, uma vez que o recenseamento tinha sido, no Brasil, o meio empregado para obter elementos mais amplos sobre o assunto.

Assim, ressalta-se que as dificuldades sobre a categoria cor, haviam sido registradas já no Censo de 1940, deste modo, em conformidade com instruções expressas no censo Demográfico de 1940, as respostas, quanto a cor, deveriam limitarse a qualificação conforme a raça, se: preta, branca e amarela. Destacou-se também, que

\footnotetext{
2 Partes como: Censo Agrícola, Censo Industrial, Censo Comercial, Mercado de Crédito, Atividades Auxiliares do Comercio, Censo dos Serviços são compostas por outras centenas de tabelas que revelam dados sobre cada uma das 26 Unidades que compunham a Federação na década de 1950.

${ }^{3}$ Conforme IBGE (1957, v. 6, p. xii) [...] Não se obteve o levantamento total da população aborígene. Informações indiretas e parciais foram obtidas, no entanto, por intermédio das declarações alusivas à côr e a língua falada.
}

Revista da ABPN • v. 12, n. Ed. Especial - Caderno Temático: "Africanos, escravizados, libertos biografias, imagens e experiências atlânticas" • agosto de 2020, p. 613-636 
na impossibilidade de uma resposta que contemplasse uma das três categorias deveriam lançar um "traço horizontal" no local da resposta. Assinalou-se ainda, que a constituição de um grupo genérico, havia sido designado de "pardos", e que sob essa designação foram reunidos aqueles que haviam sido registrados em declaração como: índio, caboclo, mulato, moreno, etc., ou aqueles que haviam lançado um - (traço) no lugar reservado a resposta. E que [...] somente nos casos de completa omissão da resposta foi atribuída a designação "cor não declarada" [grifo no original] (IBGE, 1940, p. xxi)

Em relação ao Censo Demográfico de 1950, a declaração havia sido deixada a critério do recenseado, emprestando, assim, maior precisão aos resultados censitários. Conforme o documento, a distribuição da população brasileira segundo cor fez parte também dos Recenseamentos de 1872 e 1890. (IBGE, 1957, p. xvii-xviii)

Sobre o quesito cor, os dados gerais apresentados pelo $\operatorname{IBGE}(1957$, p. 01) para a população brasileira em percentuais estavam assim distribuídos: 61,66\% declararam-se brancos, $10,96 \%$ pretos e $26,64 \%$ pardos.

Neste sentido, intentou-se observar como os dados populacionais em percentuais sobre este quesito foram representados na Região Norte naquele censo. Desta forma, os dados sobre o quesito cor registrados para a Região Norte no documento, contradiziam aos apresentados para a Federação como se observa no quadro a seguir:

Quadro 1 - Total e Percentual Geral conforme as categorias brancos, pretos, pardos e amarelos da Região Norte Brasileira de acordo com Censo de 1950

\begin{tabular}{lllllll}
\hline $\mathbf{N}^{\mathbf{0}}$ & Região Norte & Brancos & Pretos & Pardos & Amarelos & Total Geral \\
\hline $\mathbf{0 1}$ & Total por categorias & 577.329 & 90.061 & $1.171,152$ & 1.446 & $1.839,988$ \\
$\mathbf{0 3}$ & Percentual Geral & $31,3 \%$ & $4,8 \%$ & $63,6 \%$ & $0,07 \%$ & $99,77 \%$ \\
\hline
\end{tabular}

Fonte: Construção do autor com dados constantes no IBGE (1957, V. 6, 7, 8, 9, 10-t1, 11)

Se em nível nacional, os percentuais de negros (pretos e pardos) somavam $37,6 \%$, na Região Norte pretos e pardos compunham 68,4\%, contrariando os discursos explícitos do início do século XX de que em menos de um século a população brasileira tonaria majoritariamente branca fruto das políticas de embranquecimento da nação

Revista da ABPN • v. 12, n. Ed. Especial - Caderno Temático: "Africanos, escravizados, libertos biografias, imagens e experiências atlânticas" • agosto de 2020, 
conforme Lacerda (2011 [1911]) apud Lotierzo e Scuwarcz (2013, p. 04) que assinalava “O negro passando a branco, na terceira geração, por efeito do cruzamento de raças". 4

O mesmo pode ser observado em todas as unidades que compunham a Região Norte, no que corresponde o percentual relativo às estas categorias raciais para aquele momento. Ou seja, os percentuais na referida região, revelou uma população preponderante negra. Este detalhe pode ser observado nos quadros 2 e 3 :

Quadro 2 - Computo Geral da População conforme as categorias brancos, pretos, pardos e amarelos por Estados e Territórios que Compunham a Região Norte Brasileira de acordo com Censo de 1950

\begin{tabular}{llllll}
\hline $\mathbf{N}^{\mathbf{0}}$ & Local & Brancos & Pretos & Pardos & Amarelos \\
\hline $\mathbf{0 1}$ & Estado do Amazonas & 189.376 & 17.410 & 305.320 & 557 \\
$\mathbf{0 2}$ & Estado do Pará & 325.281 & 59.744 & 734.574 & 875 \\
$\mathbf{0 3}$ & Território Federal do Acre & 34.438 & 5.980 & 74.161 & 10 \\
$\mathbf{0 4}$ & Território Federal do Amapá & 10.175 & 3.052 & 24.186 & 02 \\
$\mathbf{0 5}$ & Território Federal do Rio Branco & 7.528 & 898 & 9.648 & 01 \\
$\mathbf{0 6}$ & Território Federal do Guaporé & 10.531 & 2.977 & 23.263 & 01 \\
$\mathbf{0 7}$ & Total & 577.329 & 90.061 & $1.171,152$ & 1.446 \\
$\mathbf{0 8}$ & Total Geral 1.839,988 & - & - & - & - \\
\hline
\end{tabular}

Fonte: Construção do autor com dados constantes no IBGE (1957, V. 6, 7, 8, 9, 10-t1,

11)

Quadro 3 - Percentual Populacional Comparativo conforme as categorias brancos, pretos, pardos e amarelos - Brasil, Estados e Territórios que Compunham a Região Norte Brasileira de acordo com Censo de 1950

\begin{tabular}{llllll}
\hline $\mathbf{N}^{\mathbf{0}}$ & Local & Brancos & Pretos & Pardos & Amarelos \\
\hline $\mathbf{0 1}$ & Brasil & 61,66 & 10,96 & 26,64 & 0,63 \\
\hline
\end{tabular}

\footnotetext{
${ }^{4}$ Conforme Schwarcz (2011, p. 226) João Baptista de Lacerda foi um cientista, e Intelectual de renome nacional. Formou-se em medicina pela Faculdade do Rio de Janeiro, bem como foi autor de diversas pesquisas na área de fisiologia e microbiologia, tendo exercido atividades de relevo durante sua carreira. Conforme a autora, Lacerda foi ministro da Agricultura e, no Museu Nacional, atuou como chefe do Laboratório Experimental e como subdiretor das seções de zoologia, antropologia e paleontologia. Segundo Schwarcz, boa parte das investigações de João Batista Lacerda resultou em artigos publicados na renomada Revista do Museu Nacional. A autora assinala também que este foi diretor do Museu Nacional, além de presidente da Academia Nacional de Medicina e foi escolhido para representar o Brasil no Congresso Universal das Raças, realizado em Londres em 1911.
}

Revista da ABPN • v. 12, n. Ed. Especial - Caderno Temático: "Africanos, escravizados, libertos biografias, imagens e experiências atlânticas” • agosto de 2020, 


\begin{tabular}{llllll}
\hline $\mathbf{0 2}$ & Estado do Amazonas & 36,84 & 3,39 & 59,43 & 0,10 \\
$\mathbf{0 3}$ & Estado do Pará & 28,96 & 5,32 & 65,39 & 0,08 \\
$\mathbf{0 4}$ & Território Federal do Acre & 30,01 & 5,21 & 64,63 & 0,01 \\
$\mathbf{0 5}$ & Território Federal do Amapá & 27,15 & 8,14 & 64,53 & 0,01 \\
$\mathbf{0 6}$ & Território Federal do Rio & 41,55 & 4,96 & 53,26 & 0,00 \\
& Branco & & & & \\
$\mathbf{0 7}$ & Território Federal do Guaporé & 28,51 & 8,06 & 62,99 & 0,44 \\
\hline
\end{tabular}

Fonte: Construção do autor com dados constantes no IBGE (1957, V. 1, 6, 7, 8, 9, 10$\mathrm{t} 1,11)$

A este respeito, estes dados contribuem para a compreensão de uma "supremacia demográfica negra" no computo populacional dos estados e territórios que compunham a Região Norte brasileira nos anos de 1950. Nesse sentido, destaca-se que o conceito de "supremacia demográfica negra" foi cunhado por que Fonseca (2007), ao realizar um estudo sobre o contingente de pretos, pardos, crioulos e cabras nas escolas mineiras no século XIX. Assim sendo, este autor demonstrou que a polução negra era numericamente superior, a não negra, nas localidades pesquisadas por este nos distritos mineiros de: Caeté, Passagem, São Gonçalo e São Bartolomeu, Bom Fim, Redondo e Cachoeira do Campo nos meados do século XIX. Sobre o assunto, Dutra (2017), também constatou, a mesma situação no quantitativo populacional em percentuais para a Província de Mato Grosso, para o município de Cuiabá, bem como a parte urbana desta mesma cidade em 1890 ao tratar de pretos e pardos letrados na cidade de Cuiabá nos oitocentos. ${ }^{5}$

Em se tratando das unidades que compunham a Região Norte nos anos de 1950, é possível observar que no Estado do Pará, os dados apresentados foram os seguintes: aqueles que haviam declarado-se como pardos correspondia a 65,39\%, os brancos, a 28,96\% e pretos a 5,32\%. Em relação ao Território Federal do Acre IBGE (1957, V. 7, p. 71) registrou para o quesito "cor" cômputos percentuais de 30,01\% para brancos, $5,21 \%$ para pretos e $64,63 \%$ para pardos.

\footnotetext{
${ }^{5}$ Conforme Dutra (2017, p. 59) a população não branca do município de Cuiabá era de $69,8 \%, 71,4 \%$ para toda a Província e 70,7\% para os residentes na parte urbana da cidade de Cuiabá.
}

Revista da ABPN • v. 12, n. Ed. Especial - Caderno Temático: "Africanos, escravizados, libertos biografias, imagens e experiências atlânticas" • agosto de 2020, 
A esse respeito, para o Território Federal do Rio Branco IBGE (1957, V. 9, p. 67) ressaltou-se que os brancos perfaziam um total de $41,55 \%$, os pretos de $4,9 \%$ e os pardos de 53,26\%. Quanto ao Estado do Amazonas IBGE (1957, V. 8, p. 73) assinalou que os percentuais da população foram assim destacados: brancos compunham 36,94\%, os pretos $3.39 \%$ e pardos 59,43\%. Já para o Território Federal do Amapá foram computados os seguintes percentuais: $27,17 \%$ para brancos, $8,14 \%$ para pretos e $64,53 \%$ para pardos.

Nesse sentido, reservou-se o Território Federal do Guaporé para esta parte final, por se tratar do espaço, onde as experiências de homens negros e mulheres negras nas regiões que o compunham foram registrados em documentos presentes no Arquivo de Mato Grosso, e por observar que assim como nas outras unidades que compunham a Região Norte, o conceito de "supremacia demográfica negra" também pode ser aplicado para o contexto populacional do referido território. Desse modo, em conformidade com o IBGE (1957) o Território do Guaporé foi criado através do Decreto-Lei 5812 de 13 de setembro de 1943. Conforme o documento, para a constituição deste território foi desmembrado terras dos Estados do Amazonas e Mato Grosso. De acordo com o documento na ocasião da realização do censo em 1950, a porção de terras correspondente ao território em questão era distribuída entre dois municípios (Guajarámirim e Porto Velho), nove distritos, duas cidades e sete vilas. (p. IX)

Para um panorama geral a respeito da composição populacional residente no território Federal do Guaporé em 1950, o Censo apresentou dados que revelaram um quantitativo de 36.935 habitantes para o referido território. ${ }^{6}$ Sobre este quantitativo populacional assinala-se que após a realização de uma contagem, o pesquisador percebeu que a soma do número de homens para as categorias apresentadas em relação ao município de Guajará-Mirim totalizavam 5.580, cerca de 25 a menos do computo estabelecido no Censo. Nesse sentido, a soma dos números apresentados para as categorias de brancos, pretos e pardos é de 5.580 diferindo do valor apresentado pelo Censo de 1957 que é de 5.605. O mesmo ocorre para o número de mulheres, desse modo, a soma realizada pelo pesquisador é 4.066, diferindo também do resultado

\footnotetext{
${ }^{6}$ Ver IBGE (1957, p. 64), e Perdigão \& Basségio (1992, p. 176).
}

Revista da ABPN • v. 12, n. Ed. Especial - Caderno Temático: "Africanos, escravizados, libertos biografias, imagens e experiências atlânticas" • agosto de 2020, p. 613-636 
apresentado pelo Censo que é de 4.086. Assim sendo, pela soma feita pelo pesquisador a população de Guajará era de 9.646 habitantes, por tanto, 45 habitantes a menos.

O mesmo ocorreu com o município de Porto Velho. Nesse sentido, na soma realizada pelo pesquisador obteve-se um total de 15.246 habitantes do sexo masculino, ao passo que Censo havia apresentado um quantitativo de 15.311. Situação idêntica aconteceu com a contagem sobre o número de mulheres. A esse respeito, a soma realizada pelo pesquisador foi de 11.879, diferindo dos 11.933 apresentados pelo Censo de 1957. Assim sendo, construídas estas observações, assinala-se que conforme as somas realizadas pelo pesquisador, o cômputo populacional para o Território Federal do Guaporé para aquela data era de 36.771 habitantes. Nesse sentido, destaca-se que segundo IBGE (1957, p. 64) esse quantitativo estava distribuído entre as categorias raciais da seguinte forma:

Quadro 4 - Quantitativo Populacional residente no Território Federal do Guaporé conforme as categorias Raciais nominadas pelo IBGE - brancos, pretos e pardos no Censo de $1950 .^{7}$

\begin{tabular}{clll}
\hline Localidade & Brancos & Pretos & Pardos \\
\hline Guajará-mirim & 2427 & 818 & 6401 \\
Porto Velho & 8104 & 2159 & 16862 \\
Total $=\mathbf{3 6 7 7 1}$ & 10531 & 2977 & 23263 \\
\hline
\end{tabular}

Fonte: Construção do autor a partir dos dados contidos na tabela de número 37 em IBGE (1957, p. 64)

No quadro a seguir apresenta-se o percentual da população presente no Território Federal do Guaporé para os municípios de Guajará-Mirim e Porto Velho no que corresponde as categorias utilizadas pelo IBGE no Censo divulgado em 1957, o destaque ficou para os $63,2 \%$ pardos no computo da população do referido território.

Quadro 5 - Percentual da População nos municípios que compunham o Território Federal do Guaporé conforme as categorias Raciais nominadas pelo IBGE - brancos, pretos e pardos presentes no Censo de 1950

\begin{tabular}{llll}
\hline & Brancos & Pretos & Pardos \\
\hline Guajará-mirim & $6,6 \%$ & $2,2 \%$ & $17,4 \%$ \\
\hline
\end{tabular}

\footnotetext{
${ }^{7}$ As informações numéricas contidas nos quadros 4 e 5 estão em conformidade com soma realizada pelo pesquisador dos dados quantitativos apresentados na tabela de número 37 do $\operatorname{IBGE}(1957$, p. 64)
}

Revista da ABPN • v. 12, n. Ed. Especial - Caderno Temático: "Africanos, escravizados, libertos biografias, imagens e experiências atlânticas” • agosto de 2020, p. 613-636 


\begin{tabular}{cccc}
\hline Porto Velho & $22 \%$ & $5,8 \%$ & $45.8 \%$ \\
Total = 36771 & $28,6 \%$ & $8 \%$ & $63,2 \%$ \\
\hline Fonte: Construção do autor a partir dos dados contidos na tabela de número 37 em IBGE (1957, p. 64)
\end{tabular}

No quadro abaixo reunimos pretos e pardos na categoria "negros". Nesse sentido, assinala-se que o uso das categorias branco, preto e pardos neste estudo, não possui conotação biológica. Destaca-se que as utilizamos em conformidade com o sentido dado pelo IBGE ao empregá-las na contagem populacional brasileira. Igualmente, evidencia-se que o enfoque dado a categoria "negros" está em conformidade com as Diretrizes Curriculares para a Educação das Relações Étnico raciais para o Ensino da História e Cultura Afro-brasileira (BRASIL, 2003, p. 14) que esclarece que [...] ser negro no Brasil, não se limita as características físicas [...]. Conforme o documento, pesquisadores e pesquisadoras de diferentes áreas, em seus estudos unem informações pertinentes a pretos e pardos sob a categoria negros, por entenderem, conforme sugere o Movimento Negro, que esta categoria é constituída por aqueles e aquelas que reconhecem a sua ascendência africana. (IDEM, IBIDEM)

Desse modo, negros computam $71,2 \%$ do quantitativo da população residente no Território Federal do Guaporé. A este respeito, observe o quadro abaixo:

Quadro 6 - Percentual da População do Território Federal do Guaporé conforme as categorias Raciais Brancos e Negros conforme dados do IBGE/Censo de 1950

\begin{tabular}{cll}
\hline & Brancos & Negros \\
\hline Guajará-mirim & $6,6 \%$ & 19,6 \\
Porto Velho & $22 \%$ & $51.6 \%$ \\
Total = 36771 & $28,6 \%$ & $71,2 \%$ \\
\hline Fonte: Construção do autor a partir dos dados contidos na tabela de número 37 em IBGE (1957, p. 64)
\end{tabular}

No quadro 7 encaminhamos nossa observação para a área em que o estudo comprometeu-se em apresentar os registros sobre a população negra nos documentos existentes no Arquivo Público de Mato Grosso, localizado na cidade de Cuiabá. Note-se que o percentual para a população negra é expressivo no cômputo geral do município de Guajará-Mirim, restando para os não negros aproximadamente 1/4 do contingente.

Quadro 7 - Percentual da População do Município de Guajará-Mirim conforme as categorias Raciais Brancos e Negros conforme dados do IBGE/Censo de 1950

Revista da ABPN • v. 12, n. Ed. Especial - Caderno Temático: "Africanos, escravizados, libertos biografias, imagens e experiências atlânticas” • agosto de 2020, 


\begin{tabular}{ccccc}
\hline & Brancos & $\mathbf{\%}$ & Negros & $\mathbf{\%}$ \\
\hline Guajará-mirim & 2427 & $25,1 \%$ & 7219 & $74,8 \%$ \\
Total = 9646 & $25,1 \%$ & - & $74,8 \%$ & - \\
\hline Fonte: Construção do autor a partir dos dados contidos na tabela de número 37 em IBGE (1957, \\
\end{tabular}

Ademais, realizada a mostra sobre o percentual populacional conforme as categorias raciais utilizadas pelo IBGE no Censo de 1950, passa-se a seguir a percorrer a segunda parte deste estudo. Versar sobre o negro nos documentos preservados no APMT.

\section{O NEGRO NOS REGISTROS DOS DOCUMENTOS DO ARQUIVO PÚBLICO DE MATO GROSSO}

O leitor e/ou a leitora pode estar se perguntando sobre como uma população majoritariamente negra se constituiu na região do Vale do Guaporé, nesse sentido, sugere-se a apreciação da temática nas seguintes obras: Volpato (1993) em Cativos do Sertão, Assis (1988) em Contribuição para o estudo do negro em Mato Grosso, Ayala (1914) Album Gráfico do Estado de Mato Grosso, e principalmente Silva (1995) em Mistura das Cores (Política de Povoamento e População na Capitania de Mato Grosso - Século XVIII). Estes autores e autoras trazem contribuições sobre as experiências do processo de escravização do negro em Mato Grosso, bem como explicam as dinâmicas da construção da população desde a Capitania no Século XVIII (período colonial), e Província no Século XIX (período imperial) apontando para compreensão como sugeriu Dutra $(2017$, p. 53-58) para uma supremacia demográfica negra na população matogrossense.

Para encaminhar a questão do registro de homens negros e mulheres negras em documentos do Arquivo Público do Estado de Mato Grosso, assinala-se que telegramas, abaixo assinados, processos, ofícios, portarias, imagens e outros tipos de documentos constituíam-se os espaços onde estes/estas apareceram nos conteúdos registrados nos documentos presentes tanto no APMT, como também em acervos particulares. A este respeito, o leitor pode se questionar: De que maneira o autor pode confirmar o

Revista da ABPN • v. 12, n. Ed. Especial - Caderno Temático: "Africanos, escravizados, libertos biografias, imagens e experiências atlânticas” • agosto de 2020, 
pertencimento racial destas mulheres e destes homens? Nesse sentido, pesquisadores e pesquisadoras que debruçam a compreender questões concernentes ao negro na história brasileira, deparam-se com uma série de dificuldades. A esse respeito, Matos (1998) ao tratar do sumiço da cor nas fontes assinalou que isto:

[...] consiste num dos processos mais intrigantes e irritantes, ocorridos no século XIX, do ponto de vista do pesquisador. Todos que tentaram trabalhar com a história do negro, após o fim do cativeiro, já se decepcionaram com quase a impossibilidade de alcançá-los, seja trabalhando com processos-crimes e até mesmo com registros civis (MATOS, 1998, p. 97).

Sobre esta situação, uma possibilidade para poder descobrir o pertencimento racial dos sujeitos em questão, pode se dar através dos Censos Demográficos. ${ }^{8}$ Outra possibilidade seria recorrer às fichas individuais que os recenseadores detidamente preenchiam por cada unidade domiciliar.

Respondendo ao possível questionamento do/da leitor/leitora, destaca-se que uma forma que utilizou-se para identificar a cor dos sujeitos deste estudo se deu através dos relatos orais colhidos nos meses de julho de 2008, e janeiro de 2009 com cinco professoras negras que foram formadas no Colégio Santa Terezinha, a partir de $1933 .{ }^{9}$ Obteve-se ainda um álbum de imagens ofertado pela professora Isabel de Oliveira Assunção formada também na referida escola. Por outro lado, foram estas professoras que experienciaram as práticas na escola guaporeana, que testemunham os feitos e disseram quem era quem na ciranda das relações daquele espaço. A cor, a ocupação/função, e etc.

A este respeito, a partir do álbum fotográfico, trouxe-se a fotografia como forma de revelar "a cor" dos sujeitos. ${ }^{10}$ Nesse sentido, o álbum recebido continha dezesseis

\footnotetext{
${ }^{8}$ Prova disto é o Recenseamento de 1890 realizado na cidade de Cuiabá, que constava as seguintes categorias: nome, idade, profissão, raça, estado civil, religião, nacionalidade, instrução, defeitos físicos. Nesse sentido, o Censo Demográfico de 1950 apresentou as seguintes categorias e/ou características individuais: sexo, idade, cor, religião, estado conjugal, nacionalidade, naturalidade, instrução, atividade, língua falada e fecundidade.

${ }^{9}$ Sobre o Colégio Santa Terezinha ver DUTRA, Paulo Sérgio. Memórias de Professoras Negras no Guaporé: do silêncio à palavra. 2010. 149f. Dissertação (Mestrado em Educação) - Instituto de Educação - UFMT - Universidade Federal de Mato Grosso, Cuiabá, 2010.

${ }^{10} \mathrm{Um}$ conjunto de 23 fotografias foi apresentado no anexo da dissertação de mestrado de Paulo Sérgio Dutra, defendida em fevereiro de 2010, intitulada: Memórias de Professoras Negras no Guaporé: Do Silêncio à Palavra, no anexo da obra.
}

Revista da ABPN • v. 12, n. Ed. Especial - Caderno Temático: "Africanos, escravizados, libertos biografias, imagens e experiências atlânticas" • agosto de 2020, p. 613-636 
páginas, e oitenta e seis (86) imagens em preto e branco. Outra professora (Alexandrina do Nascimento Gomes) ofertou nove (9) imagens e sete (7) documentos/portarias.

Sobre este conjunto de imagens, ressalta-se que este trouxe o cotidiano, os eventos e/ou fatos sobre a vida das gentes que residiam na região do Guaporé e na cidade de Guajará-Mirim. As imagens propiciaram localizar eventos como: o dia a dia do Colégio Santa Terezinha, o passeio de Dom Rey com as educandas em um barco chamado Apóstolo, e em um caminhão que o Bispo havia conseguido para os afazeres da escola e Prelazia conforme relatou Assunção (jan. 2009). Há ainda, o registro de um evento em que as educandas aparecem uniformizadas e perfiladas provavelmente, em um momento próximo da conclusão da formação, em um evento cívico, ou até mesmo um acontecimento da igreja. A exemplo disto abaixo ilustrou-se com uma imagem que evidenciava provavelmente uma atividade pedagógica realizada com as alunas do Colégio, observe:

Figura 1 - Evento Cotidiano no Colégio Santa Terezinha na cidade de GuajaráMirim/RO década de 1930

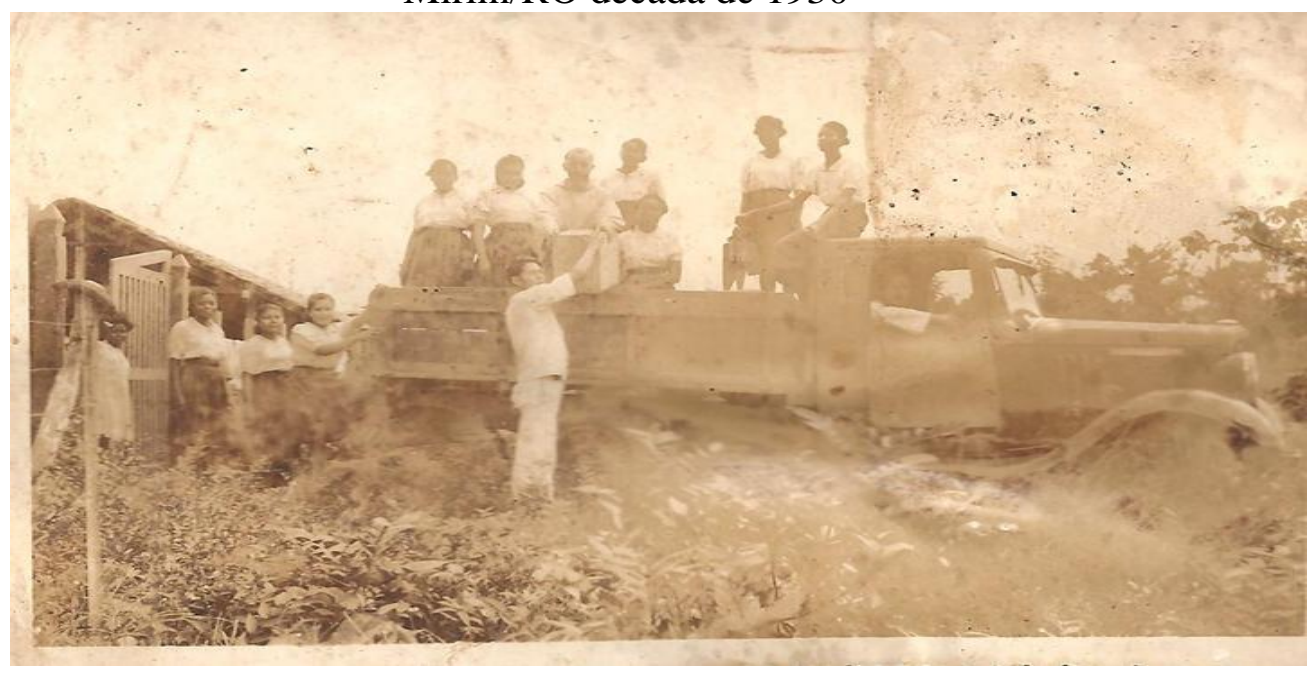

Fonte: Acervo Particular da Professora Isabel de Oliveira Assunção, janeiro de 2008.

Destacou-se também, um registro onde Dom Rey aparece com um grupo de seis (6) indígenas. Desse modo, no álbum ofertado pela professora Isabel de Oliveira

Revista da ABPN • v. 12, n. Ed. Especial - Caderno Temático: "Africanos, escravizados, libertos biografias, imagens e experiências atlânticas” • agosto de 2020, p. 613-636 
Assunção foi possível observar também, a realização de matrimônios, de cerimonias do exército, registro da infância, onde aparecerem irmãos e irmãs, e ainda a família nuclear.

O registro do cotidiano na sala de aula, pode ser encontrado nas experiências com as educandas sob a responsabilidade de Dom Rey, bem como o exercício da docência pela Professora Alexandrina do Nascimento Gomes. A esse respeito, observou-se que em uma das imagens, a hipótese da (a Professora Alexandrina) realização da chamada em uma turma de quinze (15) alunos para registrar a presença e/ou ainda vivenciando possivelmente, a correção de uma atividade. Em outra imagem pode-se observar que a professora posou com seus alunos e alunas para o registro fotográfico.

No conjunto de imagens ofertado pela Professora Alexandrina do Nascimento Gomes, observou-se o registro da visita do presidente João Batista Figueiredo, acompanhado de ministros/ministra, e ainda de políticos locais na cidade de Costa Marques/Príncipe da Beira/RO. ${ }^{11}$ Nesse sentido, conforme as imagens, a professora Alexandrina apareceu ladeada pelo presidente República, pela Ministra da Educação e Cultura Esther de Figueiredo Ferraz e pelo Governador Coronel Jorge Teixeira. ${ }^{12}$

Entre estas imagens, observou-se também o registro de cursos de formação de professores/professoras que era realizado em época de férias.

\footnotetext{
${ }^{11}$ Ver Os Presidentes e a República (2001, p. 161-169) em que assinala que João Batista de Oliveira Figueiredo exerceu o cargo de Presidente da Republica entre 15 de março de 1979 e 13 de março 1985. Disponível em: file:///D:/Meus\%20Documentos/Documents/2018/2019/Publica\%C3\%A7\%C3\%B5es_2019/Os\%20presi dentes\%20e\%20a\%20rep\%C3\%BAblica\%20-\%202001.pdf. Acesso em: 14 de fevereiro de 2019.

12 Sobre a passagem com a professora Alexandrina do Nascimento Gomes ver Dutra (2010) parte denominada de "ANEXOS - Imagens reveladoras do cotidiano da época", mais especificamente Figura 5 (p. 116). No tocante a Esther de Figueiredo Ferraz, ela foi Ministra da Educação no governo do presidente João Batista Figueiredo entre 1982 e 985, sendo a primeira mulher a ocupar o cargo de ministra no Brasil. Nesse sentido, consultar texto disponível em: http://portal.mec.gov.br/cne/arquivos/pdf/2008/nota\%20de\%20falecimento\%20da\%20exministra\%20ester\%20figueiredo.pdf. Acesso em: 15 de fevereiro de 2019. A respeito de Jorge Teixeira de Oliveira Foroni (2013) destacou que o mesmo foi nomeado governador do Território Federal de Rondônia em 13 de abril de 1979, promoveu a criação do Estado de Rondônia, permanecendo no cargo até 14 de maio de $1985 . \quad$ Disponível http://www.snh2013.anpuh.org/resources/anais/27/1364929577_ARQUIVO_PaolaForoni.pdf._Acesso em: 15 de fevereiro de 2019.
}

Revista da ABPN • v. 12, n. Ed. Especial - Caderno Temático: "Africanos, escravizados, libertos biografias, imagens e experiências atlânticas” • agosto de 2020, 
Sobre a presença do gênero nas imagens encontramos tanto homens, quanto mulheres. A esse respeito, as mulheres são maioria nas fotografias, elas ocupam sempre o plano central da imagem, e protagonizam os eventos/fatos/acontecimentos já mencionados, sendo a aluna, a matriarca, a professora, a religiosa, a secretaria de educação. Os homens, por sua vez aparecerem como: o patriarca, o noivo, o sacerdote, o soldado, e o politico. A infância também é representada, principalmente as meninas, que integram a família, e aparecem em passeios, no cotidiano escolar e religioso.

Sobre os homens negros, observou-se que estes incorporavam os conteúdos de telegramas, ofícios e abaixo assinados que reportavam a realidade e/ou demandas das localidades da região do Vale do Guaporé. A esse respeito, eles foram encontrados incorporando as listas de nomes de pais e/ou tutores nos abaixo assinados para requerer a criação de escolas. Sobre essa situação, ressalta-se que Norberto Pedroso Quintão integrava a lista de oito pais que conforme o documento [...] sentiam a necessidade de uma escola para ensino de meninos de ambos os sexos [...] (TELEGRAMA, 1931, p. 03) na povoação de Rolim de Moura do Guaporé em 1931. A esse respeito, destaca-se que Norberto Pedroso Quintão como sugere o abaixo assinado, fosse pai de Vicência Quintão de onze anos, Antônia Quintão nove anos e Francisca Quintão sete anos, meninas que integravam a lista das vinte cinco crianças em idade escolar na localidade de Rolim de Moura do Guaporé.

Sobre o número de crianças, no referido documento, observou-se que entre os vinte cinco nomes, doze (12) delas eram meninas e treze (13) meninos. Provavelmente, Norberto Pedroso Quintão fosse um homem negro, pai da juíza de paz e professora negra Antônia Quintão que integrou a primeira turma de alunas/professoras formadas na escola de Dom Rey.

Sobre a presença destes homens, nos documentos encontrados, estes (os documentos) não os citavam diretamente, porém, estes os assinavam. Outros documentos veicularam demandas similares ao exemplo dado acima, é o caso da solicitação dos moradores e moradoras de outras localidades, como o caso da transferência da escola rural mista de Ilha das Flores para Costa Marques conforme requereu o Delegado Joaquim Cesário em 07 de julho de 1940. E ainda, o pedido da [...] creação de escolas rurais em Pedras Negras e Limoeiro do Rio Guaporé [...] povoações

Revista da ABPN • v. 12, n. Ed. Especial - Caderno Temático: "Africanos, escravizados, libertos biografias, imagens e experiências atlânticas" • agosto de 2020, p. $613-636$ 
bastante povoadas e regular o numero de creanças em idade escolar [...] (TELEGRAMA, 193?) feito pelo prefeito do município de Guajará-Mirim Carlos Rocha Leal. $^{13}$

Sobre a presença dos sujeitos nos documentos analisados no APMT, destaca-se que as mulheres foram protagonistas de processos de pedidos de contratação de adjuntas para auxiliá-las, mudança de nome ao vivenciar matrimônio, e incorporavam ainda, as listas de professoras interinas nos Relatórios de Instrução pública, principalmente nos anos de 1923 e 1942.

Sobre o tema, o cenário a seguir é uma mostra sobre estas mulheres.

\section{MULHERES NEGRAS NO GUAPORÉ A LUZ DOS DOCUMENTOS ENCONTRADOS NO ARQUIVO PÚBLICO DE MATO GROSSO}

Para os registros sobre as mulheres negras nos documentos na região do Vale do Guaporé, assinala-se ter percorrido as caixas de documentação presentes no Arquivo Público do Estado de Mato Grosso. São caixas de metal e/ou papel que guardam documentos correspondentes à instrução pública, a segurança pública, à administração pública, Relatórios de Instrução Pública e outros. A esse respeito, a pesquisa foi desenvolvida durante o segundo semestre de 2008 e primeiro de 2009. Na ocasião lançou-se mão de ofícios, telegramas, atas, requerimentos e etc. Nesse sentido, destacase que inicialmente deparou-se com a presença da Professora Emília Bringel Guerra.

Sobre a referida professora assinala-se que conforme o Relatório de Instrução Pública sobre as atividades escolares do ano de 1922, Emília Birngel Guerra atuava como professora Interina na Escola Mista de Generoso Ponce uma povoação situada entre Santo Antônio do Madeira e Guajará-Mirim, em 13 de março de 1922, em conformidade com o Relatório do Diretor Geral de Instrução Pública, apresentado pelo

\footnotetext{
${ }^{13}$ Conforme informações no sitio Portal Guajará, o odontólogo Carlos Rocha Leal exerceu o cargo de prefeito da cidade de Guajará-Mirim entre 14 de março de 1937 e 03 de setembro de 1943. Dados Disponíveis em: http://www.portalguajara.com/os-prefeitos-de-guajara-mirim-por-aluizio-da-silva/. Acesso em: 14 de fevereiro de 2019.
}

Revista da ABPN • v. 12, n. Ed. Especial - Caderno Temático: "Africanos, escravizados, libertos biografias, imagens e experiências atlânticas" • agosto de 2020, p. $613-636$ 
Dr. Cesário Alves Correia ao Secretario Geral do Estado em 15 de março de 1924. (RELATÓRIO DE INSTRUÇÃO PÚBLICA, 1924, p. 08)

Ainda se ressalta que na portaria de número 172 datada de 3 de agosto de 1927, indicavam que a professora Emília Bringel Guerra havia sido exonerada do cargo de docente da escola mista da povoação de Generoso Ponce e, no dia 9 do mesmo mês, através da Portaria n. 70, D. Jandyra de Souza havia sido nomeada para substituí-la. Anos depois, conforme relatos, a professora Emília Bringel foi designada para lecionar na Escola Reunida de Guajará-Mirim, sendo demitida por razões políticas, segundo informou a professora Isabel de Oliveira (dez. 2009): “[...] então por política demitiram ela né, que foi a nossa primeira diretora a mãe da irmã Maria Emília, era uma viúva. Então, ele [Dom Rey] pegou ela.” [...] para ser a professora no Colégio Santa Terezinha.

Conforme Dutra (2010, p. 87) a convite de Dom Rey, a Professora Emília Bringel Guerra atuou nos primeiros anos do Colégio Santa Terezinha, ensinando as primeiras letras para as meninas do Guaporé e que carinhosamente era chamada pelo apelido de Dona Pretinha pelas educandas do referido colégio. O autor assinalou também que através dos relatos, pode-se observar a importância do trabalho realizado por esta professora nos primeiros anos do Santa Terezinha, pois, sem ela, as primeiras aulas não teriam acontecido, haja vista conforme Oliveira (dez. 2009), ter sido ela a recepcionista das meninas no porto do rio Mamoré, em Guajará-Mirim, acolhendo-as e acomodando-as.

Para além da sala de aula Emília Bringel Guerra, reivindicou direitos. Nesse sentido, documentaram-se através de um telegrama o pedido do pagamento de Três Contos e Duzentos mil Réis (3: 200,000) correspondente aos vencimentos de seu falecido esposo José Joaquim Guerra referentes ao interstício de junho a dezembro de 1931 a janeiro de 1932. Sobre o assunto, destaca-se que o documento foi datado de 17 de maio de 1935 veiculado pela Secção de Contabilidade do Thesouro, assinado por Eulálio Alves Guerra denominado Oficial Maior Addido.

Em 1935, conforme relatou Oliveira (dez. 2009) dona Pretinha ficou muito doente e viajou para Manaus a fim de realizar um tratamento de saúde, pois, segundo informou a entrevistada: "[...] a saúde dela foi se abalando"; e conforme noticiaram membros da sua família que residia em Manaus, dona Pretinha se estabeleceu ali

Revista da ABPN • v. 12, n. Ed. Especial - Caderno Temático: "Africanos, escravizados, libertos biografias, imagens e experiências atlânticas” • agosto de 2020, p. 613-636 
definitivamente. Para continuar sua obra, Dom Rey trouxe as irmãs Calvarianas para substitui-la nas atividades do Colégio Santa Terezinha.

A saga da Professora Paula Gomes de Oliveira também foi registrada por Dutra (2010). Nesse sentido, o autor ressaltou que a referida professora integrou a primeira turma de alunas do Colégio Santa Terezinha criado por Dom Francisco Xavier Rey em Guajará-Mirim. Conforme Dutra, após a formação das primeiras professoras, Dom Rey fundou em 1938 uma escola na povoação de Limoeiro, e destinou a professora Paula Gomes Oliveira para exercer a docência. ${ }^{14}$

Sobre a trajetória desta professora, em $1^{\circ}$ de março de 1939 em conformidade com o Relatório de Instrução Pública de 1942 ela foi nomeada professora na escola rural mista de Limoeiro. Foram nomeadas também, outras oito professoras naquela ocasião conforme o documento.

A esse respeito, para além da participação nas atividades docentes, as professoras formadas na escola de Dom Rey, atuavam como interlocutoras frente aos problemas existentes em suas comunidades, como catequistas e agentes de saúde. Desse modo, elementos como a demanda por professoras/professores para atuar nas escolas do Guaporé foi motivo para endossar a construção de vários documentos encontrados no APMT, a exemplo de dois processos, um de n. 1.092 e o outro de n. 1.097, datados, respectivamente, do ano de 1942. Nesse sentido, estes processos traziam informações sobre um mapa mensal de frequência, no qual também constavam nomes de alunos que frequentavam as escolas públicas nas povoações de Limoeiro e Pedras Negras.

No documento, pode-se observar que ao lado dos nomes dos alunos e alunas, e foi deixado um espaço destinado ao registro de faltas e das notas das lições, que poderiam ser caracterizadas como: ótimas, boas, regulares, sofríveis e péssimas. Havia, ainda, um espaço reservado para que fossem feitas algumas observações, no qual as professoras Paula Gomes de Oliveira e Eremita Cordeiro deixaram suas assinaturas ao lado do visto do inspetor escolar. O processo no qual a professora Paula Gomes era a

\footnotetext{
${ }^{14}$ Dutra (2010, p. 68-69) apresenta um quantitativo de 20 escolas criadas por Do Francisco Xavier Rey, conforme o autor em cada uma destas escolas o religioso colocou uma das professoras formadas para exercer a docência.
}

Revista da ABPN • v. 12, n. Ed. Especial - Caderno Temático: "Africanos, escravizados, libertos biografias, imagens e experiências atlânticas" • agosto de 2020, p. 613-636 
parte interessada, constava de nove páginas, incluindo um mapa mensal de frequência e a aplicação dos alunos da Escola Rural Mista de Limoeiro, correspondente ao mês de março. Como observou-se, esse processo tramitou entre os dias 23 e 24 de junho de 1941, presumindo-se, devido ao pouco espaço de tempo, que houve certa urgência em solucionar o pedido das requerentes. Todavia, o que figura como conteúdo mais importante dos processos são os pedidos da nomeação de adjuntas para auxiliá-las nas escolas de Limoeiro e Pedras Negras. Para auxiliá-la, a professora Paula Gomes de Oliveira indicava o nome de Maria de Jesus Evangelista, e a professora Eremita Cordeira o nome de Sebastiana Diniz.

Sobre a professora Paula Gomes de Oliveira, Oliveira (jan. 2009) destacou que esta possuía outro dom além da docência, tocava cavaquinho, e promovia exibições durante suas aulas e nas comemorações festivas de sua comunidade. Pouco se sabe sobre sua atuação. Assinala-se que a sua carreira no magistério, apenas que foi curta, visto ter falecido jovem.

Sobre a passagem de mulheres guaporeanas em documentos existentes no APMT, destaca-se que muitas delas cumpriram trajetórias na educação, cargos na administração publica, e simbólicos. Sobre a trajetória delas, principalmente na área da educação, sugere-se uma leitura atenciosa dos seguintes trabalhos: Memórias de Professoras Negras no Guaporé. Do Silencio a Palavra de Dutra (2010), A escola de Dom Francisco Xavier Rey: história da formação de professoras no Vale do Guaporé de Nascimento (2014), e Entre o Evangelho e o Ensino Rural: Educação Feminina no Instituto Nossa Senhora do Calvário (Vale do Guaporé/Guajará-Mirim/MT/RO 1933/1976) de Souza (2017).

Entre elas estão: Verena Leite Ribeiro, e Teodora Cruz provenientes de Vila Bela da Santíssima Trindade/MT, Alexandrina do Nascimento Gomes, Maria de Jesus Evangelista, Patrícia Gomes, Isabel de Oliveira Assunção, Antônia Quintão provenientes das povoações localizadas na região do Vale do Guaporé a tecer as trilhas do conhecimento e espargir as luzes das letras na região de mesmo nome.

\section{CONSIDERAÇÕES FINAIS}

Revista da ABPN • v. 12, n. Ed. Especial - Caderno Temático: "Africanos, escravizados, libertos biografias, imagens e experiências atlânticas” • agosto de 2020, p. 613-636 
Considera-se que o presente texto ao apresentar o cenário populacional em percentuais da região Norte do Brasil, sob o ponto de vista de Censo de 1950, contribui no sentido de perceber uma superioridade demográfica negra como assinalaram Fonseca (2007) em uma pesquisa realizada sobre a população mineira nos meados dos séculos XIX e Dutra (2017) sobre a realidade de pretos e pardos na instrução pública matogrossense nos oitocentos. Destaca-se que o escrito, constitui-se como contradição as noções do pensamento social brasileiro que expressavam nos últimos anos do século XIX e primeiras décadas do século XX a ideia de embraquecimento da nação. A esse respeito, os percentuais de todas as unidades que formavam a Região Norte na década de 1950 em consonância com o Censo daquele momento refutavam tal ideia.

Por outro lado, considera-se que o estudo em questão reforça o conjunto de pesquisas realizadas sobre o negro nas historicidades da educação brasileira, auxiliando na compreensão de um movimento constituído nos últimos 17 anos por pesquisadores/pesquisadoras, muitos/as deles/as negras/os colocando a temática das relações raciais no centro da questão retirando o negro da invisibilidade defendida por Aquino, Santana, Santana e Junior (2013).

Outra questão observada no estudo foram os conteúdos veiculados nos documentos presentes no APMT, e recebidos das localidades existentes no Vale do Guaporé, em que "as gentes” suplicavam a criação de escolas, a mudança e/ou transferência de uma escola para outra localidade, e a contratação de professoras adjuntas para auxiliar as mestras na região guaporeana. A este respeito, o conjunto de documentos analisados mostrou que as populações daquelas localidades estavam antenadas com o setor burocrático na capital do Estado de Mato Grosso. Sobre o conjunto de documentos, homens e mulheres apareceram como sujeitos. Neste contexto, o destaque ficou para as mulheres negras na qualidade de professoras das escolas de lugares como: Limoeiro, Pedras Negras, Santo Antônio, e outros. Como professoras elas foram as irradiadoras das luzes do conhecimento por todas as localidades encravadas no vale do Guaporé, espaço geográfico que compreende os arredores da cidade de Vila Bela da Santíssima Trindade/MT e até a cidade de Guajará-Mirim/RO.

\section{REFERENCIAS BIBLIOGRÁFICAS}

Revista da ABPN • v. 12, n. Ed. Especial - Caderno Temático: "Africanos, escravizados, libertos biografias, imagens e experiências atlânticas" • agosto de 2020, 
AQUINO. Mirian Albuquerque, SANTANA. Sergio Rodrigues de, SANTANA. Leyde Klebia Rodrigues de, JUNIOR. Jobson Francisco da Silva. Temas sobre o/a negro/a: Uma analise da produção de conhecimento no curriculum Lattes. Revista da Associação Brasileira de Pesquisadores/as Negros/as (ABPN), v. 5, n. 9, 2013, p. 172-187.

ASSIS, Edvaldo de. Contribuição para o estudo do negro em Mato Grosso. Cuiabá: UFMT/PROED, 1888.

ASSUNÇÃO, Isabel de Oliveira. Entrevista concedida a P. S. Dutra, integrante do GEM/IE/UFMT. Guajará-Mirim, ago. 2008 e jan. 2009. 2 fitas cassete (80 min) 3 1/2 pps, estéreo.

AYALA, S. CARDOSO S. F. Album Graphico do Estado de Matto-Grosso. Hamburgo: Ayala, 1914.

BRASIL. Diretrizes Curriculares Nacionais para a Educação das Relações Étnicorraciais para o Ensino de História e Cultura Afro-Brasileira e Africana. Brasília, DF: MEC/SEPPIR, out., 2004.

Recenseamento de 1890: Freguesia da Sé - $1^{\circ}$ Distrito - Cuiabá Mato-Grosso Brasil. In: PERARO, Maria Adenir. (Coord.). Levantamento de fontes censitárias: o recenseamento de 1890 em Mato Grosso. Cuiabá: PIBIC/CNPq/UFMT, ago. 2002/jul. 2003. 1 CD-ROM.

Disponível

Ministério da Educação, Conselho Nacional de Educação. Nota de Falecimento.

http://portal.mec.gov.br/cne/arquivos/pdf/2008/nota\%20de\%20falecimento\%20da\%20ex-

ministra\%20ester\%20figueiredo.pdf. Acesso em: 13 de fevereiro de 2019.

DIRETORIA GERAL DE INSTRUÇÃO PÚBLICA. Portaria no. 172 de 03 de agosto de 1927, onde Emília Bringel Guerra é exonerada do cargo de professora das Escolas Reunidas de Guajará-Mirim através do $109^{\circ}$ Relatório de Instrução Pública apresentado ao Senhor Secretário do Interior Justiça e Finanças, pelo Diretor Geral de Instrução Pública. APMT - 1927.

. Relatório da Diretoria Geral de Instrução Pública do Estado de Mato Grosso, referente ao ano de março 1924 informando que Emília Birngel Guerra atuava como professora Interina na Escola Mista de Generoso Ponce localidade situada entre Santo Antônio do Madeira e Guajará-Mirim, em 13 de março de 1922. Cuiabá, em 15 de março de 1924. APMT - 1924.

Relatório da Diretoria Geral de Instrução Pública do Estado de Mato Grosso, referente ao ano de 1942, apresentando dados sobre nomeação de professores para as escolas dos municípios mato-grossenses onde são nomeadas: Antônia Quintão, Paula Gomes de Oliveira e Eremita Cordeiro. Cuiabá, 25 de fevereiro de 1943. APMT - 1942.

Processo através do qual a Professora Paula Gomes de Oliveira solicita uma professora adjunta para auxiliá-la numa escola localizada na povoação de Limoeiro, no Guaporé. GuajaráMirim, 24 de junho de 1941. APMT - 1941 A, lata antiga.

. Processo através do qual a Professora Eremita Cordeiro solicita uma professora adjunta para auxiliá-la numa escola localizada na povoação de Limoeiro, no Guaporé. Guajará-Mirim, 24 de junho de 1941. APMT - 1941 A, lata antiga.

Revista da ABPN • v. 12, n. Ed. Especial - Caderno Temático: "Africanos, escravizados, libertos biografias, imagens e experiências atlânticas” • agosto de 2020, p. 613-636 
Regulamento de Instrução Pública Primária do Estado de Mato Grosso, Cuiabá, outubro de 1942. APMT - 1942.

DUTRA, Paulo Sérgio. Memórias de Professoras Negras no Guaporé. Do Silencio a Palavra. 2010. 140 f. Dissertação (Mestrado em Educação)- Universidade Federal de Mato Grosso, Instituto de Educação, Programa de Pós Graduação em Educação, Cuiabá, 2010.

Paulo Sérgio. Ao correr da penna: pretos e pardos letrados na cidade de Cuiabá/MT nos oitocentos. 452 f. Tese (Doutorado em Educação)- Programa de Pós Graduação em Educação, Universidade Federal Fluminense, Niterói, 2017.

FONSECA, Marcus Vinicius. Pretos, pardos, crioulos e cabras nas escolas mineiras do século XIX. Tese (Doutorado em Educação)- Programa de Pós Graduação em Educação, Faculdade de Educação, Universidade de São Paulo, São Paulo, 2007.

FORONI. Paola Conceição. Jorge Teixeira de Oliveira, primeiro governador de Rondônia, entre $a$ modernidade $e \quad a$ cordialidade. Disponível em: http://www.snh2013.anpuh.org/resources/anais/27/1364929577_ARQUIVO_PaolaForoni.pdf. Acesso em 15 de fevereiro de 2019.

GUAJARÁ-MIRIM. Departamento de Correios e Telégrafos. [Telegrama: pedido do delegado Joaquim Cesário para transferência da escola rural de Ilha das Flores para Costa Marques]. 07 de julho de 1940.

Departamento de Correios e Telégrafos. [Telegrama: Abaixo-assinado da população de Rolim de Moura do Guaporé enviado ao Delegado Fiscal do Norte do estado de Mato Grosso, requerendo a criação de uma escola na localidade]. 1931 - APMT - 1931.

Departamento de Correios e Telégrafos. [Telegrama: requerimento de Emília Bringel Guerra pedindo o pagamento de Três Contos e Duzentos mil Réis (3:200,000), correspondente aos vencimentos de seu falecido esposo José Joaquim Guerra referentes ao interstício de junho a dezembro de 1931 a janeiro de 1932]. 1935 - APMT - 1935.

Departamento de Correios e Telégrafos. [Telegrama: requerimento da criação de escolas rurais nas povoações de Pedras Negras e Limoeiro, no Vale do Guaporé feito pelo prefeito do município de Guajará-Mirim Carlos Rocha Leal]. 193? - APMT - 193 ?.

IBGE. Recenseamento Geral do Brasil de 1940. Disponível em: https://biblioteca.ibge.gov.br/visualizacao/periodicos/65/cd_1940_v2_br.pdf. Acesso em: 22 de janeiro de 2019.

Recenseamento Geral do Brasil de 1950. Disponível em: https://biblioteca.ibge.gov.br/visualizacao/periodicos/67/cd_1950_v1_br.pdf. Acesso em: 13 de fevereiro de 2019.

Conselho Nacional de Estatística Serviço Nacional de Recenseamento. Território Federal do Guaporé: Censos Demográfico e Econômico. Série Regional, Vol. 6; Rio de Janeiro, 1957.

Revista da ABPN • v. 12, n. Ed. Especial - Caderno Temático: "Africanos, escravizados, libertos biografias, imagens e experiências atlânticas” • agosto de 2020, 
https://biblioteca.ibge.gov.br/visualizacao/periodicos/67/cd_1950_v6_territorio_guapore.pdf . Acesso em: 22 de janeiro de 2019.

Conselho Nacional de Estatística Serviço Nacional de Recenseamento. Território Federal do Rio Branco: Censos Demográfico e Econômico. Série Regional, Vol. 9; Rio de Janeiro, $1957 . \quad$ Disponível em: https://biblioteca.ibge.gov.br/visualizacao/periodicos/67/cd_1950_v9_territorio_rio_branco.pdf. Acesso em: 22 de janeiro de 2019.

Conselho Nacional de Estatística Serviço Nacional de Recenseamento. Território Federal do Acre: Censos Demográfico e Econômico. Série Regional, Vol. 7; Rio de Janeiro, $1957 . \quad$ Disponível em: https://biblioteca.ibge.gov.br/visualizacao/periodicos/67/cd_1950_v7_territorio_ac.pdf. Acesso em: 22 de janeiro de 2019.

Conselho Nacional de Estatística Serviço Nacional de Recenseamento. Território Federal do Amapá: Censos Demográfico e Econômico. Série Regional, Vol. 11; Rio de Janeiro, $1957 . \quad$ Disponível em: https://biblioteca.ibge.gov.br/visualizacao/periodicos/67/cd_1950_v11_ap.pdf . Acesso em: 22 de janeiro de 2019.

Conselho Nacional de Estatística Serviço Nacional de Recenseamento. Estado do Amazonas: Censos Demográfico e Econômico. Série Regional, Vol. 8; Rio de Janeiro, 1957. Disponível em: https://biblioteca.ibge.gov.br/visualizacao/periodicos/67/cd_1950_v8_am.pdf. Acesso em: 22 de janeiro de 2019.

Conselho Nacional de Estatística Serviço Nacional de Recenseamento. Estado do Pará: Censos Demográfico e Econômico. Série Regional, Vol. 10 t1; Rio de Janeiro, 1957. Disponível em: https://biblioteca.ibge.gov.br/visualizacao/periodicos/67/cd_1950_v10_t1_pa.pdf . Acesso em: 22 de janeiro de 2019.

LACERDA, João Batista de (1912). O Congresso Universal das Raças reunido em Londres (1911): apreciação e commentarios. Museu Nacional, Rio de Janeiro: (2011 [1911]). Sobre os mestiços no Brasil. Tradução de "Sur le métis au Brésil" (Premier Congrès Universel des Races : 26-29 juillet 1911, Paris, Devouge, 1911), In:_História, Ciências, Saúde - Manguinhos. RJ, v.18, n.1, jan.-mar.

LOTIERZO, T. H. P.; SCHWARC, L. K. M. Raça, gênero e projeto branqueador: "a redenção de Cam", de modesto brocos. 2013. Disponível em: http://cral.in2p3.fr/artelogie/spip.php?page=imprimir_articulo\&id_article=254. Acesso em: 23 de novembro de 2018.

MATTOS, Hebe Maria. Das cores do silencio: os significados da liberdade no Sudeste escravista, Brasil Século XIX. Rio de Janeiro: Nova Fronteira, 1998.

NASCIMENTO, Silvio Melo do. A escola de Dom Francisco Xavier Rey: história da formação de professoras no Vale do Guaporé. 2014. 132 f. Dissertação (Mestrado em Educação) Fundação Universidade Federal de Rondônia, Programa de Pós-Graduação em Educação, 2014.

PERDIGÃO, Fracinete; BASSEGIO, Luís. Migrantes Amazônicos - Rondônia: A trajetória da Ilusão. São Paulo, Edições Loyola, 1992.

Revista da ABPN • v. 12, n. Ed. Especial - Caderno Temático: "Africanos, escravizados, libertos biografias, imagens e experiências atlânticas" • agosto de 2020, p. 613-636 
SCHWARC, L. K. M. Previsões são sempre traiçoeiras: João Baptista de Lacerda e seu Brasil branco. Fontes, v. 18, n. 1, jan., - mar, 2011, p. 225-242. Disponível em: http://www.scielo.br/pdf/hcsm/v18n1/13.pdf. Acesso em: 23 de novembro de 2018.

SILVA, Jovam Vilela da. Mistura das Cores (Política de Povoamento e População na Capitania de Mato Grosso - Século XVIII). Cuiabá: Edufmt, 1995.

SOUZA, Cleicineia Oliveira de. Entre o Evangelho e o Ensino Rural: Educação Feminina no Instituto Nossa Senhora do Calvário (Vale do Guaporé/Guajará-Mirim/MT/RO 1933/1976). 2017. 164 f. Dissertação (Mestrado em Educação)- Universidade Federal de Mato Grosso, Instituto de Educação, Programa de Pós Graduação em Educação, Cuiabá, 2017.

VOLPATO, Luiza Rios Ricci. Cativos do Sertão: Vida cotidiana e escravidão em Cuiabá em 1850-1888. São Paulo: Editora Marco Zero; Cuiabá, MT: Editora da Universidade Federal de Mato Grosso, 1993.

Recebido 03/07/2020

Aprovado em 22/07/2020

Revista da ABPN • v. 12, n. Ed. Especial - Caderno Temático: "Africanos, escravizados, libertos biografias, imagens e experiências atlânticas" • agosto de 2020, 